\title{
Association of PER2 and CRY1 Polymorphisms with the Morningness-Eveningness in Korean Adults
}

\author{
Jung Hie Lee, MD, $\mathrm{PhD}^{1,2}$, Seong Jae Kim, MD, $\mathrm{PhD}^{3}$, Se Yong Lee, $\mathrm{MS}^{1}$, \\ Jun-Won Hwang, MD, $\mathrm{PhD}^{1}$, In Bum Suh, MD, $\mathrm{PhD}^{4}$ \\ 'Departments of Psychiatry, ${ }^{4}$ Laboratory Medicine, Kangwon National University Hospital, Chuncheon, Korea \\ 2Division of Sleep \& Circadian Disorders, Department of Medicine, Brigham \& Women's Hospital, Harvard Medical School, Boston, MA, USA \\ ${ }^{3}$ Department of Psychiatry, Naeane Hospital, Wonju, Korea
}

\begin{abstract}
Background and Objective Individuals have a unique circadian preference, which is based on differences in endogenous rhythm and environmental factors. There has been no study on the relationship between the morningness-eveningness (ME) preference and the polymorphisms of PER2 and CRY1 genes, which may play an essential role in the modulation of circadian rhythm. Our present study aims to examine the difference in the polymorphisms of PER2-2221A/G and CRY1-2790T/G, which are related to a greater cancer risk, according to the ME preference.
\end{abstract}

Methods The Korean version of the Morningness-Eveningness Questionnaire was administered and buccal DNA samples were obtained from 425 Korean adults aged 18 years or older. We excluded subjects who were being treated for sleep disorders or those with shift work. 47 morning type (MT) (age: $44.57 \pm 12.33, \mathrm{M}: \mathrm{F}=14: 33$ ) subjects, 59 neither type (NT) (age: $35.20 \pm 9.53, \mathrm{M}: \mathrm{F}=20: 39$ ) subjects and 51 evening type (ET) (age: $28.80 \pm 8.03, \mathrm{M}: \mathrm{F}=14: 37$ ) subjects were finally included in the present study. The above candidate single nucleotide polymorphisms were analyzed by DNA sequencing or a SNaPshot assay.

Results For the PER2-2221A/G and CRY1-2790T/G, there were no significant differences in the genotype distribution, allele frequency, or proportion of $\mathrm{G}$ allele positive subjects between the MT and ET groups. There was no significant difference in the mean scores of the MEQ-K, KESS, or PSQI between G allele positive and negative subjects for either PER2-A2221A/G or CRY1-2790T/G.

Conclusions Our study did not support the association of the ME preference with the PER2-2221 A/G and CRY1-2790T/G in Korean adults.

Sleep Med Res 2015;6(2):60-65

Key Words Morningness-eveningness, Cancer risk, PER2-2221A/G, CRY1- 2790T/G, Korean adults.

Received: April 21, 2015

Revised: June 5, 2015

Accepted: June 22, 2015

Correspondence

Jung Hie Lee, MD, PhD

Department of Psychiatry,

Kangwon National University Hospital,

156 Baengnyeong-ro, Chuncheon 24289,

Korea

Tel $+82-33-258-2310$

Fax +82-33-256-3344

E-mail jhielee@kangwon.ac.kr

\section{INTRODUCTION}

Circadian rhythm, the endogenous expression of a rhythmic variable with a period of approximately 24 hours, has been displayed for various physiological variables, such as body temperature, heart rate, blood pressure, and hormonal levels. ${ }^{1,2}$ Individuals have a unique circadian preference, which is based on differences in endogenous rhythm and environmental factors influenced by various demographic factors including age and gender. ${ }^{3}$ It is known that the endogenous circadian rhythm is generated and modulated by the suprachiasmatic nucleus, and that circadian rhythmicity is essentially controlled by a self-sustaining transcriptional/ translational feedback loop, in which the expression of putative "clock genes" is suppressed periodically by their protein products. ${ }^{4,5}$

Since it was originally reported by Katzenberg et al. ${ }^{6}$ that the CLOCK gene polymorphism (3111C allele) was associated with diurnal preference, there have been other studies on various genetic polymorphisms, including those of the PER and casein kinase 1 (CK1) genes, associated with diurnal preference ${ }^{7}$ or circadian rhythm sleep disorder. ${ }^{8-11}$ In particular, the PER family of genes are known to play key roles in the molecular mechanism of generating circadian rhythm by a negative auto-feedback loop. ${ }^{11}$ In animal experiments, the mutation of the PER gene causes an arrhythmicity ${ }^{12}$ or a short free-running period..$^{13}$ 
PER2, of the PER family of genes, is considered to play a critical role in behavioral rhythmicity. ${ }^{12}$ Toh et al., ${ }^{10}$ reported that the PER2 polymorphism at the CK1 binding loci was associated with familial advanced sleep phase syndrome (FASPS). This result suggests that the PER2 polymorphism is an essential factor in advanced sleep phase syndrome (ASPS), which has the characteristic of the shortening of the circadian period (tau). ${ }^{10}$

Previous studies have reported the association of the PER3 polymorphism with morningness-eveningness (ME) preference, ${ }^{11,14}$ as well as delayed sleep phase syndrome (DSPS), ${ }^{14}$ however, there has been no study on the relationship of the PER2 polymorphism with ME preference. In particular, it has been reported that the PER2 gene induced apoptosis through the upregulation of tumor suppressor genes, and that the PER2 gene mutation (S662G) found in ASPS affected tumor occurrence in rats. ${ }^{15}$ When the CRY gene and the PER gene form a heterodimer, it plays an important role in the modulation of circadian rhythm, ${ }^{1}$ influencing cell growth. ${ }^{1}$ Recent studies have shown a relationship between the risk of breast cancer and the polymorphisms of various sleep-related genes in female night shift workers. ${ }^{15}$ The single nucleotide polymorphism (SNP) of the CRY1 G/T allele has also been linked to an increased risk of breast cancer in the general population. ${ }^{16}$

To date, there has been no study on the relationship between the ME preference and the polymorphisms of the PER2 and CRY1 genes, which have been hypothesized to play an essential role in the modulation of circadian rhythm. We hypothesized that each polymorphism of PER2-2221A/G and CRY1$2790 \mathrm{~T} / \mathrm{G}$ would be associated with the ME preference in Korean adults. Our present study aims to examine the difference in the polymorphisms of PER2-2221A/G and CRY1-2790T/G according to the ME preference in the Korean adult population.

\section{METHODS}

\section{Participants}

The present study was conducted on subjects aged 18 years or older who visited the Chuncheon National Museum or the Health Promotion Center at Kangwon National University Hospital and Hyosung Hospital in Korea between May 2010 and February 2012. The Korean version of the Morningness-Eveningness Questionnaire (MEQ-K) ${ }^{17}$ the Korean version of the Epworth Sleepiness Scale (KESS), ${ }^{18}$ and the Pittsburgh Sleep Quality Index (PSQI) ${ }^{19}$ translated into Korean, were administered to 2011 subjects. Buccal DNA samples were obtained from 400 subjects, who agreed to donate a buccal swab for the genetic study. The study protocol was approved by the Institutional Review Board at Kangwon National University Hospital. Written informed consent was obtained from each enrolled patient. All procedures were carried out in accordance with the principles of the Declaration of Helsinki.

\section{Procedures}

Standard scores on the MEQ were used to categorize subjects as morning type (MT), neither type (NT) or evening type (ET). The lower scores (16 to 41) indicated ET, the higher scores (59 to 86) indicated MT and a score of 42 to 58 indicated an NT.

Among the collected DNA samples $(n=400)$, there were only 62 samples from ET subjects. We selected the same number of samples $(n=62)$ from each of the MT and NT groups. 62 DNA samples were selected among the MT subjects in the order of highest MEQ-K scores, and 62 samples among the NT subjects according to an equal number before and after the median MEQK score of the NT group.

Two previously-reported SNPs, PER2 A2221G and CRY1 T2790G, which had not been associated with the ME type, were further pursued as candidate alleles for morning or evening preference, and were analyzed by DNA sequencing or a SNaPshot assay.

We excluded the subjects who were being treated for sleep disorders $(n=4)$ or those with shift work $(n=8)$. The data for 47 MT (age: $44.57 \pm 12.33, \mathrm{M}: \mathrm{F}=14: 33$ ) subjects, 59 NT (age: $35.20 \pm 9.53, \mathrm{M}: \mathrm{F}=20: 39$ ) subjects, and $51 \mathrm{ET}$ (age: $28.80 \pm$ $8.03, \mathrm{M}: \mathrm{F}=14: 37)$ subjects, were included in the final gene analysis after discarding 2 failed data.

\section{Measures}

\section{DNA extraction and DNA sequencing process}

The DNA samples were obtained from the saliva by buccal smear and stored at $-80^{\circ} \mathrm{C}$. The buccal swab procedure was conducted according to the manufacturer's instructions. Primer pairs were designed from the sequences, and were amplified using polymerase chain reaction (PCR). PCR primers and conditions used for the amplification of potential SNPs are shown in Table 1. A Gene Amp PCR System 9700 (Applied Biosystems, Foster City, CA, USA) was used with an initial denaturation step of $95^{\circ} \mathrm{C}$ for 5 minutes, followed by 40 cycles of denaturation at $95^{\circ} \mathrm{C}$ for 15 seconds, annealing at $57^{\circ} \mathrm{C}$ or $48^{\circ} \mathrm{C}$ for $30 \mathrm{sec}-$ onds, extension at $72^{\circ} \mathrm{C}$ for 30 seconds, and a final elongation step at $72^{\circ} \mathrm{C}$ for 3 minutes. Sequencing reactions were performed in both senses with a Big Dye Terminator v3.1 Cycle Sequencing kit (Applied Biosystems, Foster City, CA, USA), and the same primers were used for sequencing analysis. Sequence reactions were run on the ABI PRISM 3700 DNA Automatic Analyzer (Applied Biosystems, Foster City, CA, USA).

\section{SNaPshot assay}

The genotyping was screened with a single base primer extension assay using the ABI PRISM SNaPShot Multiplex kit (ABI, Foster City, CA, USA) according to the manufacturer's recommendations. The PCR reactions were carried out as follows: 1 cycle at $95^{\circ} \mathrm{C}$ for 10 minutes, 35 cycles at $95^{\circ} \mathrm{C}$ for $30 \mathrm{sec}$ onds, $55^{\circ} \mathrm{C}$ for 1 minute, $72^{\circ} \mathrm{C}$ for 1 minute, followed by 1 cycle 
Table 1. PCR primers and conditions used for amplification of potential SNPs

\begin{tabular}{llllc}
\hline Gene (SNP) & rs number & Primer sequence & Annealing temperature, time \\
\hline PER2 (A2221G) & rs121908635 & Forward & $5^{\prime}$-AGAGCATCTGTGGGATGG-3' & $57^{\circ} \mathrm{C}, 30 \mathrm{sec}$ \\
& & Reverse & $5^{\prime}$-ACTCCACCCTGCATTTTAC-3' & \\
CRY1 (T2790G) & \multirow{2}{*}{ rs1056560 } & Forward & $5^{\prime}$-TTTTCCCACTGACTTCAAAA-3' & $48^{\circ} \mathrm{C}, 30 \mathrm{sec}$ \\
& & Reverse & $5^{\prime}$-GGTCAATAAACACTCATCAC-3' & \\
\hline
\end{tabular}

PCR: polymerase chain reaction, SNP: single nucleotide polymorphism.

Table 2. Demographic data in the MT, NT and ET groups

\begin{tabular}{|c|c|c|c|c|c|c|}
\hline & \multicolumn{4}{|c|}{ Mean (SD) or ratio } & \multirow{2}{*}{$\mathrm{p}$} & \multirow{2}{*}{ Bonferroni } \\
\hline & Total $(\mathrm{n}=157)$ & $\operatorname{MT}(\mathrm{n}=47)$ & $\mathrm{NT}(\mathrm{n}=59)$ & $\mathrm{ET}(\mathrm{n}=51)$ & & \\
\hline Age $\left(\right.$ year) ${ }^{* *}$ & $35.93(11.77)$ & $44.57(12.33)$ & $35.20(9.53)$ & $28.80(8.03)$ & $<0.0001$ & $\mathrm{MT}>\mathrm{NT}>\mathrm{ET}$ \\
\hline $\mathrm{M}: \mathrm{F}(\% \text { male })^{\dagger}$ & $48: 109(30.6)$ & $14: 33(29.8)$ & $20: 39(33.9)$ & $14: 37(27.5)$ & 0.76 & - \\
\hline Education (year)* & $14.60(2.86)$ & $13.60(3.87)$ & $15.14(2.38)$ & $14.89(1.94)$ & 0.02 & $\mathrm{MT}<\mathrm{NT}=\mathrm{ET}$ \\
\hline MEQ-K score**‡ & $49.76(11.99)$ & $64.77(4.48)$ & $49.88(1.13)$ & $35.78(4.25)$ & $<0.0001$ & $\mathrm{MT}>\mathrm{NT}>\mathrm{ET}$ \\
\hline KESS score ${ }^{\ddagger}$ & $8.40(3.39)$ & $7.34(3.37)$ & $8.40(3.51)$ & $9.37(3.02)$ & 0.06 & - \\
\hline PSQI score*‡ & $5.48(2.86)$ & $5.53(3.74)$ & $4.85(2.08)$ & $6.16(2.59)$ & 0.05 & $\mathrm{NT}<\mathrm{ET}, \mathrm{MT}=\mathrm{ET}, \mathrm{T}=\mathrm{NT}$ \\
\hline
\end{tabular}

${ }^{*} \mathrm{p}<0.05{ }^{* *} \mathrm{p}<0.01$ (ANOVA, ${ }^{+} \chi^{2}$ test, ${ }^{\ddagger}$ ANCOVA controlling for Age).

MT: morning type, NT: neither type, ET: evening type, MEQ: Morningness-Eveningness Questionnaire, ESS: Epworth Sleepiness Scale, PSQI: Pittsburg Sleep Quality Index.

at $72^{\circ} \mathrm{C}$ for 10 minutes. After amplification, the amplified products were purified, and the primer extension reaction was carried out for 25 cycles at $96^{\circ} \mathrm{C}$ for 10 seconds, $50^{\circ} \mathrm{C}$ for 5 seconds, and $60^{\circ} \mathrm{C}$ for 30 seconds. The reaction products were analyzed by electrophoresis in an ABI Prism 3730xl DNA analyzer, and analysis was carried out using Gene Mapper (version 4.0; Applied Biosystems, Foster City, CA, USA).

\section{Data Analysis}

Observed genotype frequencies were compared with the expected Hardy-Weinberg equilibrium values using the chi-square test.

Demographic variables and scores of the MEQ-K, KESS, and PSQI in the MT, NT, and ET groups were compared by ANOVA with post hoc contrasts when controlling for the effect of the covariate age.

The genotype distributions, allele frequencies, and proportion of subjects with a risk allele in the MT, NT, and ET groups were compared using the chi-square test. Post hoc contrasts were performed for each group compared with the other two combined groups, and the odds ratios of the risk allele frequency were obtained for an appropriate group.

All statistical analyses were performed with the SPSS software package (version 18.0, SPSS Inc., Chicago, IL, USA). Two-sided $\mathrm{p}$ values below 0.05 were considered statistically significant.

\section{RESULTS}

Genotype frequencies of both PER2-2221A/G and CRY1-
2790T/G did not deviate significantly from the Hardy-Weinberg equilibrium $\left(\chi^{2}=0.52, \mathrm{p}=0.77\right.$ for PER $2 ; \chi^{2}=0.01, \mathrm{p}=0.99$ for CRY1).

There were significant differences in the means of age and education level between the MT, NT, and ET groups $(\mathrm{p}<0.01)$. When controlling for the effect of the covariate age, there were significant differences in the mean scores of the MEQ-K ( $\mathrm{p}<$ $0.0001)$ and PSQI $(\mathrm{p}=0.05)$ between the MT, NT, and ET groups (Table 2).

For the PER2-2221A/G, there were significant differences in the genotype distribution, allele frequency, and proportion of G allele positive subjects between the MT, NT, and ET groups. From a post hoc test, neither the MT nor the ET group showed a significant difference in the AG genotype, G allele frequency, or proportion of $\mathrm{G}$ allele positive subjects compared with the other groups (Table 3).

For the CRY1-2790T/G, there were no significant differences in the genotype distribution, allele frequency, or proportion of G allele positive subjects between the MT, NT, and ET groups (Table 4).

For both the PER2-A2221A/G and CRY1-2790T/G polymorphisms, there was no significant difference in the mean scores of the MEQ-K, KESS, or PSQI between G allele positive and negative subjects.

\section{DISCUSSION}

Our present study shows statistical differences in the genotype distribution and allele frequency of PER2-2221A/G be- 
Table 3. Distribution of PER2-2221A/G in the MT $(n=47)$, NT $(n=59)$ and ET $(n=50)$ groups

\begin{tabular}{|c|c|c|c|c|c|c|c|}
\hline & \multicolumn{7}{|c|}{ PER2-2221A/G } \\
\hline & \multicolumn{3}{|c|}{ Genotypes, n (\%) } & \multicolumn{2}{|c|}{ Allele frequencies } & \multicolumn{2}{|c|}{ G-Allele, n (\%) } \\
\hline & $A A$ & $A G$ & $G G$ & $A$ & $G$ & $G(+)$ & $G(-)$ \\
\hline MT & $39(83.0)$ & $8(17.0)$ & $0(0.0)$ & 0.91 & 0.09 & $8(17.0)$ & $39(83.0)$ \\
\hline NT & $58(98.3)$ & $1(1.7)$ & $0(0.0)$ & 0.99 & 0.01 & $1(1.7)$ & $58(98.3)$ \\
\hline ET & $42(84.0)$ & $8(16.0)$ & $0(0.0)$ & 0.92 & 0.08 & $8(16.0)$ & $42(84.0)$ \\
\hline $\mathrm{p}$ (3 groups) & & & $0.02^{*}$ & & $0.02 *$ & & $0.02 *$ \\
\hline p (MT vs. ET plus NT) & & & 0.11 & & 0.12 & & 0.11 \\
\hline p (ET vs. MT plus NT) & & & 0.16 & & 0.17 & & 0.16 \\
\hline p (NT vs. MT plus ET) & & & $<0.01^{* *}$ & & $0.02 *$ & & $<0.01^{* *}$ \\
\hline Odd ratio & & & & & 10.52 & & \\
\hline
\end{tabular}

Odd ratio is represented with the odds of risk allele in MT plus ET compared to NT.

${ }^{*} \mathrm{p}<0.05,{ }^{* *} \mathrm{p}<0.01\left(\chi^{2}\right.$ test $)$.

MT: morning type, NT: neither type, ET: evening type.

Table 4. Distribution of CRY1-2790T/G in the MT $(n=46)$, NT $(n=59)$ and ET $(n=51)$ groups

\begin{tabular}{|c|c|c|c|c|c|c|c|}
\hline & \multicolumn{7}{|c|}{ CRY1-2790T/G } \\
\hline & \multicolumn{3}{|c|}{ Genotypes, n (\%) } & \multicolumn{2}{|c|}{ Allele frequencies } & \multicolumn{2}{|c|}{ G-Allele, n (\%) } \\
\hline & $T T$ & $G T$ & $G G$ & $T$ & $G$ & $G(+)$ & $G(-)$ \\
\hline MT & $30(65.2)$ & $14(30.4)$ & $2(4.3)$ & 0.80 & 0.20 & $17(34.8)$ & $30(65.2)$ \\
\hline NT & $31(52.5)$ & $23(39.0)$ & $5(8.5)$ & 0.72 & 0.28 & $28(47.5)$ & $31(52.5)$ \\
\hline ET & $27(52.9)$ & $21(41.2)$ & $3(5.9)$ & 0.74 & 0.26 & $24(47.1)$ & $28(52.9)$ \\
\hline $\mathrm{p}$ (3 groups) & & & 0.65 & & 0.34 & & 0.36 \\
\hline
\end{tabular}

$\chi^{2}$ test.

MT: morning type, NT: neither type, ET: evening type.

tween the MT, ET, and NT groups, however, this genetic difference was not found between the MT and ET groups (Table 3). Toh et al., ${ }^{10}$ originally reported that the PER2-2221A/G mutation within the casein kinase $1 \varepsilon$ binding region of PER2 could be related to the pathophysiology of FASPS through the shortening of the circadian period.

If ASPS is considered pathologically as extreme morningness, ${ }^{11,20,21}$ this SNP may be associated with the MT. Although our results showed that the proportion of G allele (PER2-2221A/ $\mathrm{G})$ positive subjects in the MT group was a little higher than in the ET group [MT with G (+): 23.2\%; ET with G (+): $17.9 \%$ ], there was no statistical difference. Moreover, this result is consistent with a previous study in which it was shown that this mutation in FASPS is not found in the Japanese population. ${ }^{9}$

There have been several studies on the association between PER gene variants and diurnal preference. ${ }^{6,711,14}$ However, the majority of subsequent recent studies regarding the PER gene could not replicate the original findings. These discrepancies may be responsible for the differences in the study population. ${ }^{11,14}$ We also investigated the association of the PER2-111C/ $\mathrm{G}$ polymorphism with diurnal preference in our study population. For the distribution of PER2-111C/G among the MT, NT, and ET groups, there were not any significant differences in genotypes, allele frequencies, or proportion of $\mathrm{G}$ allele positive subjects. This result was consistent with the study of Lee et al.,22 in 299 Korean college students, where an association of the PER2-3853G/A polymorphism (rs934945) with diurnal preference was seen, however, we have not yet investigated this in our sample.

We cannot yet conclude whether ASPS is merely an extreme of morningness on the continuum of diurnal preference. Previous pedigree studies have well illustrated that ASPS has an autosomal dominant feature with a high penetrance, additionally showing a short period in their endogenous rhythm. ${ }^{23}$ The ME preference is not determined only by the endogenous rhythm, differing from circadian rhythm sleep disorders such as ASPS. ${ }^{24}$ The ME preference is influenced by various demographic characteristics such as age, gender, living habits, and/or by psychological factors. Carpen et al., ${ }^{7}$ showed that there was no difference in PER1-T2434C polymorphism between the MT and DSPS, while showing its difference between MT and ET. This reflects an existing difference in genetic features between diurnal preference and circadian rhythm sleep disorder. We certainly need to keep in mind that our study population was different from those of previous studies.

When we additionally analyzed diurnal preference and sleep quality according to the presence and absence of the PER2$2221 \mathrm{G}$ allele, no significant association between the PER2- 
$2221 \mathrm{G}$ allele and diurnal preference was found. However, $\mathrm{G}$ allele positive subjects had a tendency towards poor sleep quality $(\mathrm{p}=0.059)$, and the PSQI scores of the NT subjects who had an extremely low incidence rate of the $G$ allele were relatively lower (Table 2). Recently, the associations between the polymorphisms of CLOCK and sleep quality were investigated, however, researchers failed to find a significant association. ${ }^{25}$ It has been shown that MT subjects had better sleep quality compared with ET subjects, ${ }^{26}$ but most studies did not report a difference in sleep quality in comparison with NT subjects. Some studies, including ours, suggest that NT subjects have better sleep quality than MT subjects. ${ }^{17,27}$

Our study shows that the occurrence rate of the PER2-2221A/ G polymorphism in the MT and ET groups was higher than in the NT group. This polymorphism could not separate the MT group from the ET group. It may be difficult to rule out the possibility that the phenotype due to the PER2 polymorphism is related to other circadian genes in our study. Therefore the genetic difference of PER2 in MT or ET subjects compared with NT subjects cannot be explained by our results alone, requiring further investigation.

Recently, the PER2 S662G mutation was reported to be linked to cell cycle progression and tumorigenesis. ${ }^{28}$ Another study found that marked 24-hour rest-activity rhythms were associated with a better quality of life, better performance status, better response, and longer survival in patients with metastatic colorectal cancer. ${ }^{29}$ Recently, significant and noteworthy associations between several polymorphisms in circadian genes and breast cancer risk were found among nurses who had worked at least three consecutive night shifts. ${ }^{15}$

It was recently suggested that circadian disruption can cause various physical illnesses. Therefore, the genetic difference in CRY1-2790T/G between the MT and ET groups was examined, and no significant difference was found on the basis of the association of the CRY1 polymorphism with cancer risk (Table 4).

Although the SNP examined in our study is located at the 3 '-untranslated region, unrelated to the changes in the RNA structure or protein sequence, ${ }^{7}$ it has been shown that the function and expression of gene products can be controlled by affecting the stability of the RNA transcript. ${ }^{30-32}$ Although we did not succeed in illustrating an association between the CRY1 polymorphism and diurnal preference, it was notable that this study was the first to examine this association. It has been reported that the knockout of Cry1 and Cry2 at the animal level led to a short and long period phenotype, respectively. ${ }^{33,34}$ However, there have been no human studies on the association of the CRY1 gene with the sleep phase syndrome or ME preference. It has only been reported that the RNA expression of the clock gene was examined for 24 hours in the buccal mucosa and the tissue from a skin biopsy, and the expression of the CRY1 gene showed a circadian pattern in line with those of the PER1 and Bmall genes. ${ }^{35}$
There are some limitations of the present study. Firstly, we should have considered the endogenous rhythm in addition to the self-questionnaire when determining the ME types. Therefore, a future study would be required on the association of $\mathrm{ME}$ preference with genetic polymorphism, measuring the endogenous rhythm in the subjects with DMT and DET, in order to verify our results.

Secondly, a post hoc power analysis revealed that the statistical power for CRY1-2790T/G obtained in our sample size was approximately 0.21 , even though the statistical power for PER2$2221 \mathrm{~A} / \mathrm{G}$ was more than 0.99 , indicating a sufficient sample size. Accordingly, the limited statistical power imposed by the modest sample size in the present study may have played a role in the non-significance of the statistical comparisons for CRY12790T/G.

In summary, we did not identify the genetic difference of PER 2-2221A/G between the MT and ET groups, although the MT and ET groups showed such a difference from the NT group. We also failed to find the association of the CRY1-2790T/G polymorphism with diurnal preference.

However, our study was the first in an Asian adult population to examine the association of the ME preference with the PER22221A/G and CRY1-2790T/G polymorphisms, which may play key roles in the modulation of circadian rhythm. In the future, the relationship of the PER2-3853G/A polymorphism with diurnal preference needs to be investigated in the Korean adult population.

\section{Acknowledgments}

The authors thank Dr. Duffy JF (Harvard Medical School), who gave comments on our subject recruitment and statistical analysis. We are grateful to the staff of Chuncheon National Museum of Art for their assistance in the recruitment of our subjects. This study was supported by the Basic Science Research Program through the National Research Foundation of Korea (NRF) funded by the Ministry of Education, Science, and Technology (2010-0003160 to JHL).

\section{Conflicts of Interest}

The authors have no financial conflicts of interest.

\section{REFERENCES}

1. Takahashi JS, Hong HK, Ko CH, McDearmon EL. The genetics of mammalian circadian order and disorder: implications for physiology and disease. Nat Rev Genet 2008;9:764-75.

2. Morris CJ, Yang JN, Scheer FA. The impact of the circadian timing system on cardiovascular and metabolic function. Prog Brain Res 2012;199: 337-58.

3. Adan A, Archer SN, Hidalgo MP, Di Milia L, Natale V, Randler C. Circadian typology: a comprehensive review. Chronobiol Int 2012;29:1153-75.

4. Young MW, Kay SA. Time zones: a comparative genetics of circadian clocks. Nat Rev Genet 2001;2:702-15.

5. Zhang J, Dong X, Fujimoto Y, Okamura H. Molecular signals of Mammalian circadian clock. Kobe J Med Sci 2004;50:101-9.

6. Katzenberg D, Young T, Finn L, Lin L, King DP, Takahashi JS, et al. A CLOCK polymorphism associated with human diurnal preference. Sleep 1998;21:569-76.

7. Carpen JD, von Schantz M, Smits M, Skene DJ, Archer SN. A silent 
polymorphism in the PER1 gene associates with extreme diurnal preference in humans. J Hum Genet 2006;51:1122-5.

8. Takano A, Uchiyama M, Kajimura N, Mishima K, Inoue Y, Kamei Y, et al. A missense variation in human casein kinase I epsilon gene that induces functional alteration and shows an inverse association with circadian rhythm sleep disorders. Neuropsychopharmacology 2004;29: 1901-9.

9. Satoh K, Mishima K, Inoue Y, Ebisawa T, Shimizu T. Two pedigrees of familial advanced sleep phase syndrome in Japan. Sleep 2003;26:416-7.

10. Toh KL, Jones CR, He Y, Eide EJ, Hinz WA, Virshup DM, et al. An hPer2 phosphorylation site mutation in familial advanced sleep phase syndrome. Science 2001;291:1040-3.

11. Archer SN, Robilliard DL, Skene DJ, Smits M, Williams A, Arendt J, et al. A length polymorphism in the circadian clock gene Per3 is linked to delayed sleep phase syndrome and extreme diurnal preference. Sleep 2003;26:413-5.

12. Bae K, Jin X, Maywood ES, Hastings MH, Reppert SM, Weaver DR. Differential functions of mPer1, mPer2, and mPer3 in the SCN circadian clock. Neuron 2001;30:525-36.

13. Shearman LP, Jin X, Lee C, Reppert SM, Weaver DR. Targeted disruption of the mPer3 gene: subtle effects on circadian clock function. Mol Cell Biol 2000;20:6269-75.

14. Pereira DS, Tufik S, Louzada FM, Benedito-Silva AA, Lopez AR, Lemos NA, et al. Association of the length polymorphism in the human Per3 gene with the delayed sleep-phase syndrome: does latitude have an influence upon it? Sleep 2005;28:29-32.

15. Zienolddiny S, Haugen A, Lie JA, Kjuus H, Anmarkrud KH, Kjærheim $\mathrm{K}$. Analysis of polymorphisms in the circadian-related genes and breast cancer risk in Norwegian nurses working night shifts. Breast Cancer Res 2013;15:R53.

16. Dai H, Zhang L, Cao M, Song F, Zheng H, Zhu X, et al. The role of polymorphisms in circadian pathway genes in breast tumorigenesis. Breast Cancer Res Treat 2011;127:531-40.

17. Lee JH, Kim SJ, Lee SY, Jang KH, Kim IS, Duffy JF. Reliability and validity of the Korean version of Morningness-Eveningness Questionnaire in adults aged 20-39 years. Chronobiol Int 2014;31:479-86.

18. Cho YW, Lee JH, Son HK, Lee SH, Shin C, Johns MW. The reliability and validity of the Korean version of the Epworth sleepiness scale. Sleep Breath 2011;15:377-84.

19. Buysse DJ, Reynolds CF 3rd, Monk TH, Berman SR, Kupfer DJ. The Pittsburgh Sleep Quality Index: a new instrument for psychiatric practice and research. Psychiatry Res 1989;28:193-213.

20. von Schantz M, Archer SN. Genetic aspects of delayed sleep phase syndrome (DSPS). J Sleep Res 2006;15(Suppl 1):5. Abstract.

21. Lack LC, Wright HR, Bootzin RR. Delayed sleep-phase disorder. Sleep Med Clin 2009;4:229-39.

22. Lee HJ, Kim L, Kang SG, Yoon HK, Choi JE, Park YM, et al. PER2 varia- tion is associated with diurnal preference in a Korean young population. Behav Genet 2011;41:273-7.

23. Jones CR, Campbell SS, Zone SE, Cooper F, DeSano A, Murphy PJ, et al. Familial advanced sleep-phase syndrome: a short-period circadian rhythm variant in humans. Nat Med 1999;5:1062-5.

24. Lack L, Bailey M, Lovato N, Wright H. Chronotype differences in circadian rhythms of temperature, melatonin, and sleepiness as measured in a modified constant routine protocol. Nat Sci Sleep 2009;1:1-8.

25. Barclay NL, Eley TC, Mill J, Wong CC, Zavos HM, Archer SN, et al. Sleep quality and diurnal preference in a sample of young adults: associations with 5HTTLPR, PER3, and CLOCK 3111. Am J Med Genet B Neuropsychiatr Genet 2011;156B:681-90.

26. Yazdi Z, Sadeghniiat-Haghighi K, Javadi AR, Rikhtegar G. Sleep quality and insomnia in nurses with different circadian chronotypes: morningness and eveningness orientation. Work 2014;47:561-7.

27. Rosenthal L, Day R, Gerhardstein R, Meixner R, Roth T, Guido P, et al. Sleepiness/alertness among healthy evening and morning type individuals. Sleep Med 2001;2:243-8.

28. Gu X, Xing L, Shi G, Liu Z, Wang X, Qu Z, et al. The circadian mutation PER2(S662G) is linked to cell cycle progression and tumorigenesis. Cell Death Differ 2012;19:397-405.

29. Mormont MC, Waterhouse J, Bleuzen P, Giacchetti S, Jami A, Bogdan A, et al. Marked 24-h rest/activity rhythms are associated with better quality of life, better response, and longer survival in patients with metastatic colorectal cancer and good performance status. Clin Cancer Res 2000;6:3038-45.

30. Guhaniyogi J, Brewer G. Regulation of mRNA stability in mammalian cells. Gene 2001;265:11-23.

31. Rousseau P, Le Discorde M, Mouillot G, Marcou C, Carosella ED, Moreau P. The 14 bp deletion-insertion polymorphism in the 3' UT region of the HLA-G gene influences HLA-G mRNA stability. Hum Immunol 2003;64:1005-10.

32. Misquitta CM, Iyer VR, Werstiuk ES, Grover AK. The role of 3'-untranslated region (3'-UTR) mediated mRNA stability in cardiovascular pathophysiology. Mol Cell Biochem 2001;224:53-67.

33. van der Horst GT, Muijtjens M, Kobayashi K, Takano R, Kanno S, Takao M, et al. Mammalian Cry1 and Cry2 are essential for maintenance of circadian rhythms. Nature 1999;398:627-30.

34. Nagashima K, Matsue K, Konishi M, Iidaka C, Miyazaki K, Ishida N, et al. The involvement of Cryl and Cry2 genes in the regulation of the circadian body temperature rhythm in mice. Am J Physiol Regul Integr Comp Physiol 2005;288:R329-35.

35. Bjarnason GA, Jordan RC, Wood PA, Li Q, Lincoln DW, Sothern RB, et al. Circadian expression of clock genes in human oral mucosa and skin: association with specific cell-cycle phases. Am J Pathol 2001;158: 1793-801. 